\title{
Piolin e Arrelia: entre o popular, o erudito e o massivo
}

Walter de Sousa*

Professor doutor pela Escola de Comunicações e Artes da Universidade de São Paulo - ECA/USP.

E-mail: waltersousa@hotmail.com

Resumo: O circo-teatro, presente na paisagem urbana de São Paulo em todo o século XX, constituiu-se em espetáculo popular baseado na hibridização cultural, com elementos da cultura erudita e da cultura de massa. Por sua vez, estas duas culturas se apropriaram do discurso circense, num processo evidente de circularidade cultural.

Palavras-chave: circo, circo-teatro, Piolin, Arrelia, São Paulo.
Abstract: The circus-theater, that could be seen at São Paulo's urban landscape throughout twentieth century, constituted itself in a form of popular performance based in the cultural hybridization, with elements from learned culture and mass culture. In turn, both of these cultures assimilated the circus discourse, in an unequivocal process of cultural circularity.

Keywords: circus, circus-theater, Piolin, Arrelia, São Paulo.

O fenômeno da comunicação contemporânea é todo atravessado pela fragmentação de recortes, pela imaterialidade de um real discursivo e,

Recebido: 30.04 .2009

Aprovado: 25.06.2009 ao mesmo tempo, pelo primado dos objetos na sociabilidade.

Muniz Sodré ${ }^{1}$

Para estudar qualquer fenômeno cultural/comunicacional do século XX é preciso se acercar de pelo menos três conceitos de cultura. $\mathrm{O}$ primeiro - não que tenha surgido anteriormente ao segundo - é o de cultura erudita, a que se contrapõe ao da cultura popular. Essa dicotomia, que remonta à Idade Média, ganha contorno de divisão - e, portanto, pressupõe um limite - a partir do século XIX, quando, na França, alguns intelectuais passam a colecionar elementos da chamada cultura do povo. Foi o início de um movimento que logo levaria a novas leituras. "Para alguns intelectuais, principalmente no final do século XVIII, o povo era interessante de uma certa forma exótica; no início do século XIX, em contraposição, havia um culto ao povo, no sentido de que os intelectuais se identificavam com ele e tentavam imitá-lo." ${ }^{2}$

A mudança se dá por meio do Romantismo. No entanto, os três pontos definidores da cultura popular apontados pelos românticos são questionáveis:
* Disponível em $<$ http://lattes.cnpq. br/6689539221649758>.

1. SODRÉ, Muniz. Ciência e método em Comunicação. In: LOPES, Maria Immacolata Vassallo de (Org.). Epistemologia da Comunicação. III Seminário Interprogramas de Pós-Graduação em Comunicação, ECA/USP, 7-8 nov. 2002. São Paulo: Loyola, 2003. p. 309.

2. BURKE, Peter. Cultura popular na Idade Moderna: Europa, 1500-1800. São Paulo: Companhia das Letras, 1995. p. 37.

3. Ibid., p. 49. 
comunicação \& educação • Ano XIV • Número 3 • set/dez 2009

4. MORIN, Edgar. Cultura de massas no século $X X$ : o espírito do tempo - 1 . Neurose. 6. ed. Rio de Janeiro: Forense Universitária, 1984. p. 14.

5. CANCLINI, Nestor Garcia. Culturas híbridas. São Paulo: Edusp, 1998. p. 362

6. No sentido dado por Antonio Gramsci.

7. MARTÍN-BARBERO, Jesús. Dos meios às mediações: comunicação, cultura e hegemonia. 2 . ed. Rio de Janeiro: Editora UFRJ, 2001. p. 180.

8. GINZBURG, Carlo. O queijo e os vermes: o cotidiano e as ideias de um moleiro perseguido pela Inquisição. São Paulo: Companhia das Letras, 1987. Prefácio à edição italiana, p. 15-34.
1. Essa cultura tem origem num periodo primitivo e atravessa, incólume, os séculos, sem transformações notáveis (sabe-se hoje que entre 1500 e 1800 as tradições estiveram muito expostas a transformações, inclusive com a participação direta das elites culturais).

2. A cultura popular é uma criação coletiva, a tradição se sobrepõe ao indivíduo (constata-se atualmente que a tradição não inibe o desenvolvimento de um estilo individual).

3. O povo é formado por pessoas incultas, que vivem perto da natureza e, por isso, desenvolvem uma cultura particular, própria. Mas teria realmente existido em algum momento histórico um purismo cultural? $\mathrm{Ou}$ tais argumentos deixam evidente somente a separação mais patente, que envolve a prevalência da cultura dominante sobre culturas subalternas?

Antes de aprofundar o terceiro problema, como define Edgar Morin ${ }^{4}$ - a cultura de massa -, um fenômeno, transversal às três culturas, já se apresenta. É o hibridismo cultural.

Canclini dá a pista:

A dificuldade de definir o que é o culto e o que é o popular deriva da contradição de que ambas as modalidades são organizações do simbólico geradas pela modernidade, mas ao mesmo tempo a modernidade - por seu relativismo e antissubstancialismo - as desgasta o tempo todo ${ }^{5}$.

Esse hibridismo esfumaça, portanto, os limites entre o erudito e o popular. Quando, no século XX, a cultura de massa se consolida, envolvendo a produção industrial simbólica para difusão a uma massa social, traz um dinamismo interno que envolve a elaboração de discursos que se apropriam de elementos culturais os mais diversos. Ela se utiliza dos meios de comunicação massivos que constroem discursos não só compreensíveis pela massa, mas capazes de agregá-la socialmente a partir de um claro processo de hegemonia ${ }^{6}$.

Uma cultura que, em vez de ser o lugar onde as diferenças são definidas, passa a ser o lugar onde tais diferenças são encobertas e negadas. $\mathrm{E}$ isso não ocorre por um estratagema dos dominadores, e sim como elemento constitutivo do novo modo de funcionamento da hegemonia burguesa, "como parte da ideologia dominante e da consciência popular"?.

A cultura de massa, uma vez elaborada a partir do processo de apropriação, por construir discursos hegemônicos, não deixa de influenciar as próprias matrizes culturais, conduzindo um complexo processo que dissolve as fronteiras do que é popular, erudito e massivo. O mecanismo de alimentação e retroalimentação simbólica é chamado por Carlo Ginzburg, a partir de um conceito de Bakhtin, de circularidade cultural $^{8}$.

Estão, pois, na arena metodológica, os quatro conceitos que aqui serão empregados para compreender o circo na construção do seu discurso cultural: as matrizes culturais erudita, popular e massiva, e a liga do hibridismo, que desencadeia o fenômeno da circularidade cultural. 


\section{O GRANDE CIRCO HÍBRIDO}

As lonas circenses, que no Brasil começam a ser içadas durante a primeira metade do século XIX, a partir de companhias originárias da Europa, se tornam atração urbana em São Paulo a partir do início do século XX, quando circos de touros ou de cavalos são montados na região central da cidade. Na segunda década do século já é muito comum o espetáculo agregar em sua estrutura a pantomima, encenação com poucos diálogos e mais expressão corporal, realizada em geral pelos palhaços. Essa apresentação irá, a partir daí, transformar-se até se tornar, de fato, uma encenação dramática, o que se chamará aqui, para efeitos de análise, circo-teatro.

O circo e, especialmente, o circo-teatro, encenação feita no próprio picadeiro ou num palco instalado sob a lona, vão se firmar como entretenimento popular no momento em que a cultura de massa se estabelece e cria seu discurso. Assim, o espetáculo encenado se torna obrigatório por atrair multidões e se adapta a esse público ao agregar elementos da própria cultura de massa, oriundos do rádio ou do cinema, construindo uma linguagem que será apropriada na elaboração do discurso da televisão na década de 1950.

Dois nomes despontam nesse processo e passam a ser analisados dentro do recorte de entrecruzamentos das matrizes popular, erudita e massiva: os palhaços Piolin (1897-1973) e Arrelia (1905-2005).

\section{PIOLIN: PALHAÇO POPULAR OU ERUDITO?}

Yan de Almeida Prado informa, por meio das crônicas escritas no final da década de 1920, que São Paulo contava com duas lonas fixas que atraíam o grande público e que ofereciam um espetáculo livre de dogmatismo cultural: o Circo Alcebíades e o Circo Irmãos Queirolo.

O público comporta-se como se estivesse na casa da sogra, grita, berra, diz piadas, interpela os "artistas", arma desordem à saída. Por sua vez, os palhaços e tonis não sentem peias em soltar graças tremendamente salgadas. Já se habituou o povo a considerar o circo coisa sua ${ }^{9}$.

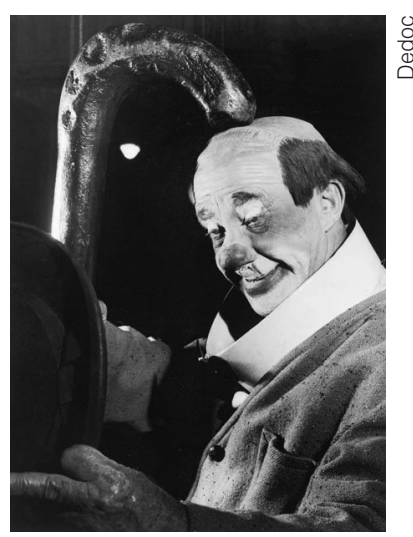

Abelardo Pinto, o palhaço Piolim

A atração principal da lona dos Queirolo é Chicharrão (Antonio Carlos Queirolo), muito popular, mas que no final da década de 1910 rompe com a família e vai atuar num circo que havia acabado de chegar à capital, o Americano, de um tal Galdino Pinto, ex-herdeiro de cartório que se apaixonou por uma artista circense e virou empresário mambembe. Chicharrão foi contracenar com o filho do empresário, Abelardo, que iniciou carreira aos sete anos como contorcionista e se fez palhaço em 1917. Suas canelas finas, que mais pareciam barbantes, lhe renderam o apelido de Piolin.

9. PRADO, Yan de Almeida. Circo de Cavalinhos, Diário Nacional de 19 de fevereiro de 1929. In: FONSECA, Maria Augusta. Oswald de Andrade: biografia. São Paulo: Editora Globo, 2007. p. 28. 
10. MACHADO, Antonio de Alcântara. Indesejáveis. Terra roxa e outras terras, ano I, n. 1, 1926, citado por PRADO, Décio de Almeida. In: ÁVILA Affonso. O modernismo. São Paulo: Editora Perspectiva, 1975. p. 142

11. MOTTA FILHO, Cândido. Piolin e o Circo de Cavalinhos. In: FONSECA, Maria Augusta. Oswald de Andrade: biografia. São Paulo: Editora Globo, 2007. p. 199

12. DANTAS, Arruda Piolin. São Paulo: Editora Parnnatz, 1980. p. 131-132. comunicação \& educação • Ano XIV • Número 3 • set/dez 2009

Os Queirolo não engoliram a afronta e planejaram o troco a Chicharrão, que logo abandonou o Circo Americano para atuar no Teatro República, no Rio de Janeiro. Foi a deixa para que os Queirolo elegessem Piolin como a sua principal atração. Vestiram-no como a Chicharrão: chapéu coco, bolota vermelha no nariz, peruca de careca, boca maquiada de branco, colarinho enorme, sapatos compridos e bengala gigante. Enfim, a caracterização que se tornaria a síntese do tipo excêntrico, adotada por boa parte das gerações seguintes de palhaços. A tradição circense consagrou dois tipos principais de palhaços: o clown, de rosto branco e vestes refinadas, e o excêntrico, que é o cômico de dupla. Enquanto o primeiro atua como escada para as situações de humor, o segundo é o desajeitado, o que destoa do real, o que se mostra, ao final, mais esperto.

Seis anos depois, já aclamado, Piolin transferiu-se para o Circo Alcebíades, instalado no mesmo Largo do Paissandu, onde atuou por cinco anos, fazendo dupla com o clown Alcebíades (Pereira).

A origem aparentemente popular do artista circense, que geralmente adquire seus saberes dentro da estrutura familiar, somado ao fato de não pertencer a uma tradicional família estrangeira, como a maioria dos seus pares circenses, fizeram de Piolin um artista genuíno aos olhos dos intelectuais de sua época. Descoberto pelo poeta franco-suíço Blaise Cendrars em 1926, ele arrastou para as arquibancadas do Alcebíades toda a geração da Semana de 22: Antônio de Alcântara Machado, Guilherme de Almeida, Di Cavalcanti, Menotti del Picchia, Oswald de Andrade, Sérgio Milliet, Tarsila do Amaral e Mário de Andrade, entre outros. Logo, Alcântara Machado assinalava na revista Terra roxa e outras terras:

São Paulo tem visto companhias nacionais de toda sorte. Incontáveis. De todas elas, a única, bem nacional, bem mesmo, é a de Piolin! Ali no Circo Alcebíades! Palavra. Piolin, sim, é brasileiro. Representa Dioguinho, o Tenente Galinha, Piolin sócio do Diabo, e outras coisas assim, que ele chama de pantomimas, deliciosamente ingênuas, brasileiras até $\operatorname{ali}^{10}$.

A descoberta de Piolin descortinou um personagem sob medida para o que demandava o anseio modernista. Como escreveu Cândido Motta Filho:

Essa descoberta foi sensacional, mormente porque se tornou o instrumento mais vivo, mais expressivo de nosso protesto. A arte, para o gosto requintado, para um público seleto, era artificial e decadente. O circo era a arte voltando à sua essência, como tudo que tinha sucesso popular, como Carlito, Mutt e Jeff ou Chicharrão ${ }^{11}$.

Ele era o personagem urbano e cosmopolita capaz de guardar em sua expressão corporal a alma brasileira, como buscavam os modernistas. Para o palhaço, foi um importante reconhecimento da sua performance como artista: "Fiz sucesso rápido devido a eles. Se interessavam por mim e constantemente escreviam crônicas sobre meu trabalho"12.

Oswald de Andrade se aproxima de Piolin atraído por sua expressão cênica. Escreve a esquete Piolin, professor de clarinete, e do palhaço retira referências para elaborar o personagem principal da sua peça $O$ rei da vela, também chamado Abelardo. Transforma o excêntrico no principal personagem do seu projeto antropofágico ao promover, em 29 de março de 1929, um banquete em que Piolin foi devorado pelos intelectuais. 
Enfim, essa apropriação e essa troca de referências confundem os limites entre o erudito e o popular? Parece que a negociação simbólica promovida pelo palhaço avançava a alma genuina buscada pelos intelectuais e levava ao picadeiro também o terceiro problema. Piolin conta a Aracy A. Amaral, no livro Tarsila, sua obra e seu tempo: "Inspirávamos-nos antes em comédias cinematográficas da época, em Carlitos sobretudo, além de outros pastelões que adaptávamos. Fazíamos um roteiro mas sempre com uma margem para a improvisação"13. Mário de Andrade também havia percebido essa influência, assinalada na revista Terra roxa e outras terras, ao analisar a pantomima Do Brasil ao far-west, de Piolin:

Outros valores que a peça contém já não o são ocasionais embora não sejam também intencionais. Aliás, a criação verdadeira nunca é intencional [...]. Por exemplo, a mistura saborosa do elemento nacional e do estrangeiro. Se esse provém diretamente do filme cowboy, não se origina de nenhuma imitação. É utilização perfeitamente plausível, deformativa sempre e que leva o absurdo a uma tal intensidade de cômico que raramente se poderá superar ${ }^{14}$.

Na década de 1950, quando a Companhia Vera Cruz buscava elaborar um produto cinematográfico que oferecesse entretenimento popular, ela procurou a referência circense. O filme dirigido pelo italiano Adolfo Celi em 1952, Tico-tico no fubá ${ }^{15}$, que conta a biografia romanceada do compositor Zequinha de Abreu, usa o estereótipo da paixão do moço da cidade pela moça do circo. Piolin surge plenamente reconhecível na tela, em sua única aparição em cinema. O filme foi o primeiro sucesso de bilheteria do estúdio e marcou a circularidade referencial entre os dois meios, o circo e o cinema. Não foi a primeira nem a única vez em que palhaços apareceram na grande tela, mas foi a primeira vez que os meios massivos se utilizaram da popularidade de um palhaço como ele para legitimar um produto que pretendia conquistar o público urbano.

Piolin também estrelou um programa na extinta TV Excelsior, em 1960, em horário nobre, antecedendo a principal atração da emissora, o programa de variedades Brasil 60, apresentado por Bibi Ferreira. A hesitação de um patrocinador fez o palhaço abandonar o projeto. Para substituí-lo, Bibi Ferreira chamou seu tio-avô, e velho desafeto de Piolin: Chicharrão, na época com quase 80 anos. Como o Largo do Paissandu, a televisão também foi o ponto de encontro dos palhaços populares.

\section{ARRELIA: PALHAÇO POPULAR OU MASSIVO?}

A presença dos dois palhaços mais antigos de São Paulo na televisão acontecia na esteira do sucesso do formato circo na TV consagrado anteriormente por três pioneiros. Em outubro de 1950 estreou na TV Tupi o programa Circo Bombril, comandado pela dupla Fuzarca (Albano Pereira Neto) e Torresmo (Brasil José Carlos Queirolo, filho de Chicharrão). Um ano depois, surge na tela da TV Paulista, e, em 1953, na da Record, o Circo do Arrelia. Waldemar Seyssel criou um dos palhaços mais conhecidos do público brasileiro, isso graças não só a sua carreira no Circo Irmãos Seyssel, da sua tradicional família ${ }^{16}$, mas também a essa atuação na Record.
13. Ibid., p. 135.

14. ANDRADE, Mário de. Do Brasil ao far-west - Piolim. Terra roxa e outras terras, São Paulo, ano I, n. 3, 1923. Disponível em: <http://www. pindoramacircus.arq. br/circos/criticas/piolin. htm>. Acesso em: 13 set. 2009.

15. TICO-TICO no Fubá. Direção de Adolfo Celi. Brasil, 1952. 1 DVD (109 min.). Coleção Vera Cruz.

16. A família é originária de Grenoble, na França, mais especificamente do Condado de Seyssel, que deu nome à família. 0 avô de Waldemar, Augusto, chegou ao Brasil em 1886, junto com o Circo Fernández. 
17. SEYSSEL, Waldemar. Arrelia e o circo. São Paulo: Melhoramentos, 1977. p. 59

18. ARRELIA. Programa Roda Viva. TV Cultura, 1993. Disponível em: <http://www.rodaviva.fapesp.br/materia/325/entrevistados/arrelia_1993. $\mathrm{htm}>$. Acesso em: 13 set. 2009.

19. ELE DEFENDE sua causa, fazer rir. Folha de S. Paulo, 27 maio 1971.

20. RUIZ, Roberto. Hoje tem espetáculo? As origens do circo no Brasil. Rio de Janeiro: Minc/ Inacen, 1987. p. 78. comunicação \& educação • Ano XIV • Número 3 • set/dez 2009

O circo dos Seyssel foi fundado pelo pai de Arrelia, Ferdinando Seyssel, o palhaço Pingapulha, e seu irmão Vicente, em 1922. Depois de viajar pelo interior do Estado, o circo chegou a São Paulo em 1940. Foi quando Arrelia encontrou sua principal expressão, a comédia de picadeiro, em que o palhaço figura como personagem central. "A temporada que fizemos no Largo da Pólvora, em São Paulo, deu-se quando comecei a tornar-me popular. Fiz grande sucesso nessa temporada, interpretando peças escritas por mim e outras de autores estrangeiros, que traduzi." ${ }^{\prime 7}$

Arrelia havia cumprido uma exigência da mãe: formar-se doutor pela Faculdade do Largo de São

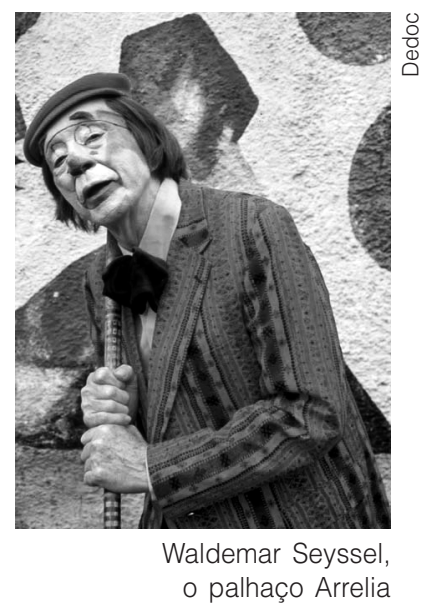
Francisco, embora tenha testemunhado, muitos anos depois, que "não queria ser advogado, queria ir para a América do Norte fazer filmes"18. Talvez por conta dessa formação, passou a escrever o que chamava de suas comedinhas, comédias de picadeiro, curtas e de humor escrachado, de que se orgulhava ser autor. Apesar da herança do pai, demonstrou personalidade suficiente para reinventar o estereótipo do palhaço excêntrico, abandonando as formas exageradas e optando por um tipo mais refinado.

Alto e desengonçado, quando todos os palhaços excêntricos são baixos, sem sapatos de bicos imensos e finos e sem bengalas compridas, falando difícil sem saber e errando sempre (boa talde). Enfim, é um tipo de rua, um misto de gente que encontrei em teatro, cinema e TV e na própria rua; um tipo que vai indo, mesmo sem instrução e metido a sebo ${ }^{19}$.

Orgânico em sua formação autoral, Waldemar Seyssel foi tradicionalista no sentido de rechaçar o circo-teatro encenado no palco, que viveu seu período de ouro nas décadas de 1940 e 1950. Por tradição familiar, ele optou pelo circo tradicional. Como não pôde escapar ao circo-teatro, pois este atraía público, ele fez das comédias de picadeiro sua principal expressão autoral. Para construir sua obra, contava com o recurso do improviso, o que tornava o personagem Arrelia coautor com Seyssel das comedinhas.

Na televisão, cada vez mais a comédia de picadeiro foi se tornando purista no sentido original da atividade circense, cada vez menos contaminada pelo circo-teatro, que ele considerava um desvirtuamento do espetáculo circense, e cada vez mais próxima do formato das entradas.

[...] mas Arrelia não tinha ilusões. Com a sua gente, ele já vinha fazendo shows no rádio e em teatros, enquanto observava caírem vertiginosamente as rendas dos circos. A crise estava instalada. Na sua opinião, começara tudo com a utilização do palco sobre o picadeiro, a introdução do teatro no circo. Para ele [...] isso desvirtuara a pureza do espetáculo circense. Não levava em conta ter sido aquilo um remédio, um paliativo para impedir a morte mais rápida do circo. Purista, queria o espetáculo na sua forma tradicional, mas como? - perguntava-se. Onde conseguir os milhões necessários à montagem de um circo atualmente? Como conciliar os investimentos com os necessários preços apenas razoáveis dos ingressos, em se tratando de um espetáculo eminentemente popular? ${ }^{20}$ 
Piolin e Arrelia - Walter de Sousa

A passagem do picadeiro para a TV foi um caminho sem volta, como testemunha o próprio Seyssel: "Entrei para a TV Record e senti enorme emoção quando dei esse passo, uma vez que ele representava um momento decisivo na minha carreira"21. O espetáculo que no circo se destinava ao público em geral, na televisão voltou-se para as crianças. $O$ palhaço da TV também não era o mesmo do picadeiro.

O palhaço na televisão foi mais puro, pois eu estava em contato direto com as famílias. No circo era diferente, ia quem queria ir. Então, eu tirei todo aquele tom malicioso, todo o duplo sentido que tinha no circo. Com a televisão veio o sucesso e vieram os fãs, que eu adoro! ${ }^{22}$

Na verdade, Seyssel, apropriando-se de comédias populares, transformou-as em comedinhas, ao seu modo. A televisão, por sua vez, ao se apropriar da linguagem do circo, levou Arrelia a retomar a velha tradição circense. Era o elemento de legitimidade de que o meio televisivo necessitava naquele momento de construção do discurso massivo. Arrelia, que poderia, à primeira vista, ser rotulado como o palhaço massivo, faz-se a partir dos elementos populares do circo familiar, além de se gabar dos dotes eruditos autorais. Ao mesmo tempo, busca em certo purismo idealizado de um circo essencial os elementos para construir o programa para a televisão. Com isso, promove a circularidade cultural.

\section{CONCLUSÃO}

O entrecruzamento dos discursos das matrizes popular, erudita e massiva, que caracteriza a linguagem dramática circense, evidencia certa transparência simbólica entre esses campos, da qual o processo de circularidade cultural expõe seus pontos de amarração.

O discurso massivo, ao se apropriar da cultura popular, além de garantir um campo simbólico reconhecível pela massa urbana, cumpre esse processo a partir de um viés político em que a mediação passa a encobrir o conflito e a resolvê-lo no imaginário popular.

Essa mediação e esse consentimento, no entanto, só foram historicamente possíveis na medida em que a cultura de massa foi constituída acionando e deformando ao mesmo tempo sinais de identidade da antiga cultura popular e integrando ao mercado as novas demandas das $\operatorname{massas}^{23}$.

Ao serem apropriados pela televisão a partir de 1950, o circo-teatro, a comédia dos palhaços e o melodrama dos autores de formação orgânica, que já haviam imitado o discurso narrativo do rádio e do cinema - revelando-se aqui um claro processo de circularidade cultural, pois se trata de apropriação de um discurso já refeito com elementos da própria cultura de massa pelo circo -, vão ser devidamente ajustados, ou mediados, na elaboração do um novo discurso. É dessa mixórdia simbólica que se extrai a graça, o riso, mesmo que sem a pintura do palhaço, da comédia massiva da televisão. De fundo, embora sem a serragem do circo cobrindo o picadeiro, ouve-se o riso inconfundível de Piolin e o eco distante de um ingênuo cumprimento: "Como vai, como vai, como vai? Como vai, como vai, vai, vai?".
21. SEYSSEL, op. cit. p. 61.

22. FORBES, Jorge. Arrelia na memória. Correio: revista da Escola Brasileira de Psicanálise, n. 13 dez. 1995. Disponível em: <http://www.jorgeforbes.com.br/br/contents. $\operatorname{asp} ? \mathrm{~s}=22 \& \mathrm{i}=39>$.

23. MARTÍN-BARBERO, op. cit., p. 181. 
comunicação \& educação • Ano XIV • Número 3 • set/dez 2009

\section{REFERÊNCIAS BIBLIOGRÁFICAS}

BURKE, Peter. Cultura popular na Idade Moderna: Europa, 1500-1800. São Paulo: Companhia das Letras, 1995.

CANCLINI, Nestor Garcia. Culturas híbridas. São Paulo: Edusp, 1998.

DANTAS, Arruda. Piolin. São Paulo: Editora Parnnatz, 1980.

ELE DEFENDE sua causa, fazer rir. Folha de S. Paulo. 27 maio 1971.

GINZBURG, Carlo. O queijo e os vermes: o cotidiano e as ideias de um moleiro perseguido pela Inquisição. São Paulo: Companhia das Letras, 1987.

MACHADO, Antonio de Alcântara. Indesejáveis. Terra roxa e outras terras, ano I, n. 1, 1926, citado por PRADO, Décio de Almeida. In: ÁVILA, Affonso. O modernismo. São Paulo: Editora Perspectiva, 1975.

MARTÍN-BARBERO, Jesús. Dos meios às mediações: comunicação, cultura e hegemonia. 2. ed. Rio de Janeiro: Editora UFRJ, 2001.

MORIN, Edgar. Cultura de massas no século XX: o espírito do tempo - 1 Neurose. 6. ed. Rio de Janeiro: Forense-Universitária, 1984.

MOTTA FILHO, Cândido. Piolin e o Circo de Cavalinhos. In: FONSECA, Maria Augusta. Oswald de Andrade: biografia. São Paulo: Editora Globo, 2007.

PRADO, Yan de Almeida. Circo de Cavalinhos, Diário Nacional de 19 de fevereiro de 1929. In: FONSECA, Maria Augusta. Oswald de Andrade: biografia. São Paulo: Editora Globo, 2007.

RUIZ, Roberto. Hoje tem espetáculo? As origens do circo no Brasil. Rio de Janeiro: Minc/Inacen, 1987.

SEYSSEL, Waldemar. Arrelia e o circo. São Paulo: Melhoramentos, 1977.

SODRÉ, Muniz. Ciência e método em Comunicação. In: LOPES, Maria Immacolata Vassallo de (Org.). Epistemologia da Comunicação. III Seminário Interprogramas de Pós-graduação em Comunicação, 7 e 8 nov. 2002, ECA/USP. Loyola: São Paulo, 2003.

TICO-TICO no Fubá. Direção de Adolfo Celi. Brasil, 1952. 1 DVD (109 min.). Coleção Vera Cruz.

CORREIO: revista da Escola Brasileira de Psicanálise, n. 13, dez. 1995.

\section{Endereços eletrônicos}

ANDRADE, Mário de. Do Brasil ao far-west - Piolin. Terra roxa e outras terras, São Paulo, ano I, n. 3, 1923. Disponível em: <http://www.pindoramacircus.arq. $\mathrm{br} /$ circos/criticas/piolin.htm>. Acesso em: 13 set. 2009.

FORBES, Jorge. Arrelia na memória. Correio: revista da Escola Brasileira de Psicanálise, n. 13, dez. 1995. Disponível em: <http://www.jorgeforbes.com.br/ $\mathrm{br} /$ contents.asp? $\mathrm{s}=22 \& \mathrm{i}=39>$.

ARRELIA. Programa Roda Viva. TV Cultura, 1993. Disponível em: $<$ http://www. rodaviva.fapesp.br/materia/325/entrevistados/arrelia_1993.htm>. Acesso em: 13 set. 2009. 